\title{
Riskli gebelerde fiziksel aktivite, gebelikte iyilik ve gebelikteki yakınmaların yaşam kalitesine etkisi: Karşılaştırmalı bir çalışma
}

\author{
The effect of physical activity, well-being in pregnancy and pregnancy complaints on quality of life in risky \\ pregnants: A comparative study \\ Esra Sabancı Baransel'1, (D) Tuba Uçar
}

${ }^{1}$ İnönü Üniversitesi, Sağlık Bilimleri Fakültesi, Ebelik Bölümü, Malatya, Türkiye

\begin{abstract}
ÖZET
Amaç: Bu çalışmada riskli olan ve olmayan gebelerin fiziksel aktivite düzeyleri, gebelikte iyilik düzeyleri ile gebelikteki yakınmaların yaşam kalitesine etkisinin incelenmesi amaçlamaktadır.

Yöntem: Kesitsel ve karşılaştırmalı tipte tasarlanan bu çalışma, Türkiye'de bir ildeki hastaneye gebelik takibi için başvuran 603 gebe ile yürütüldü (155 riskli, 448 riskli olmayan). Veriler Temmuz-Ağustos 2021 tarihleri arasında Uluslararası Fiziksel Aktivite Anketi (UFAA), Gebelikte lyilik Ölçeği (GiÖ) ve Gebelikteki Yakınmalar ve Yaşam Kalitesine Etkisi Ölçeği (GYYKEÖ) ile toplandı.

Bulgular: Riskli olan ve olmayan gebelerin UFAA, GiÖ ve GYYKEÖ puan ortalamaları karşılaştıııldı. Riskli gebeliğe sahip kadınların UFAA ve GiÖ ölçeği puan ortalamaları daha düşük, GYYKEÖ puan ortalaması ise daha yüksek ve gruplar aralarındaki farkın istatistiksel olarak anlamlı olduğu bulundu ( $p$ <.05). Lojistik regresyon sonucunda şiddetli $(O R=1.001)$ ve orta düzeyde $(O R=1.001)$ yapılan fiziksel aktivenin riskli gebeliğe karşı koruyucu rol oynadığı, riskli gebeliğe sahip olmanın gebelik endişelerinin $(\mathrm{OR}=0.900)$ varlığı, riskli olmayan gebeliğe sahip olmanın gebelikte pozitif etki ve memnuniyet $(\mathrm{OR}=1.030)$ varlığı üzerinde ön görücü rol oynadığı belirlenmiştir. Ayrıca riskli gebeliğin artmış gebelik yakınmaları ile birlikte düşük yaşam kalitesinin ön görücüsü olduğu belirlendi (OR=0.986).

Sonuçlar: Gebelik döneminde yapılan fiziksel aktivite riskli gebelerde; gebelik iyiliğini artıracağı gibi, gebelik yakınmalarını azaltmada ve yaşam kalitesini arttırmada olumlu yönde etkinlik sağlamaktadır.
\end{abstract}

Anahtar kelimeler: aktivite; gebelik; iyilik; riskli gebelik; yaşam kalitesi

\section{ABSTRACT}

Aim: This study aims to determine the effects of physical activity levels, well-being in pregnancy and complaints during pregnancy on the quality of life of risky and non-risky pregnant women.

Methods: This cross-sectional and comparative study was conducted with 603 pregnant women (155 risky, 448 non-risky) who applied to a hospital in a province in Turkey for pregnancy follow-up. Data were collected from July to August 2021 by the International Physical Activity Questionnaire (UFAA), Well-Being in Pregnancy (WiP), and Pregnancy Complaints and their Impact on Life Quality (PCILQ).

Results: BSI, WiP and PCILQ mean scores of pregnant women with and without risk were compared. BSI and WiP scale mean scores of women with risky pregnancy were lower, PCILQ mean score was higher and the difference between groups was statistically significant $(p<0.05)$. As a result of logistic regression, severe $(\mathrm{OR}=1.001)$ and moderate $(\mathrm{OR}: 1.001)$ physical activity played a protective role against risky pregnancy, the presence of pregnancy concerns $(\mathrm{OR}=0.900)$ of having a risky pregnancy, the positive effect and satisfaction of having a non-risky pregnancy in pregnancy. $(\mathrm{OR}=1.030)$ was determined to play a predictive role on its existence. In addition, it was determined that risky pregnancy was a predictor of low quality of life together with increased pregnancy complaints (OR=0.986).

Conclusion: In pregnant women with risky physical activity during pregnancy; it not only increases the well-being of pregnancy, but also provides positive effectiveness in reducing pregnancy complaints and increasing the quality of life.

Keywords: activity; pregnancy; well-being; risk pregnancy; quality of life

\section{Giriş}

Riskli gebelik, sağlıklı bir gebelik sürecinde gözlenmeyen ancak prekonsepsiyonel dönemde veya gebelik sırasında anne ve fetüsle ilgili gelişebilecek bazı komplikasyonların ortaya çıkma intimali olarak tanımlanmıştır (Daşıkan, Güner \& Bozkurt, 2019; Nascimento, Surita, Godoy, Kasawara \& Morais, 2015; Evenson ve ark., 2014; Cioffi ve ark., 2010).

Fiziksel aktivitenin mental ve sosyal sağlık üzerinde etkin bir role sahip olduğu aynı zamanda aralarında güçlü bir ilişkininde var olduğu literatürde geniş bir yere sahiptir. Fiziksel aktivitenin sağlık düzeyi üzerine etkileri incelendiğinde yaşam zorluklarına karşı toleransı arttırdığı ve genel iyilik halini oluşturma ya da arttırmaya katkı sağladığı görülmüştür. Gebelik döneminde annenin psikolojik iyilik halinin sağlanması ve gelişmesinde anne adayının yaptığı düzenli fiziksel aktivite olumlu rol oynamaktadır (Daşıkan ve ark., 2019; Nascimento ve ark., 2015; Evenson ve ark., 2014; Cioffi ve ark., 2010). Gebelikte düzenli olarak yapılan fiziksel aktivite; yalnızca gebelikle birlikte ortaya çıkan gebelik yakınmaları ve yaşam kalitesi üzerinde olumlu etki göstermeyip aynı zamanda, stres, anksiyete ve depresyon gibi psikolojik durumların gelişme riskini azalttığı, kadınların kendine olan güveni ve zindeliğini artırdığı belirlenmiştir (Daşıkan ve ark., 2019; Downs, ChasanTaber, Evenson, Leiferman \& Yeo, 2012; Evenson ve ark., 2009; Cramp \& Bray, 2010; Hui ve ark., 2012). Bu nedenle, düzenli fiziksel aktivite sağlıklı gebe kadınlar ve asgari riskleri olan gebe kadınlar için birçok gebelik kılavuzunda 
önerilmektedir (ACOG, 2002; Daşıkan ve ark., 2019; Nascimento ve ark., 2015).

Gebelik fizyolojik bir olay olmasına rağmen, fetal büyüme ve gelişmeyi sağlamak, gebe kadını doğum eylemine hazırlamak, gebelik ve doğum esnasında oluşabilecek maternal-fetal bazı risklerden korunmasını sağlamak amacıyla, anne vücudunda fizyolojik, psikolojik ve biyokimyasal bir takım değişiklikler yaşanmaktadır (Derya, Özşahin, Uçar, Erdemoğlu \& Ünver, 2018). Gebeliğe özgü olarak oluşan fizyolojik değişiklikler ile birlikte meydana gelen yakınmalar gebenin yaşam kalitesini ve gebelikte iyilik düzeyini olumsuz yönde etkileyebilmektedir. Literatürde yer alan çalışmalarda, gebelikle ilişkili fiziksel semptomlar, yorgunluk, duygusal değişimler ve yaşanan sınırlılıkların yaşam kalitesinin azalmasına neden olduğu ifade edilmiştir. Riskli olmayıp, sağlıklı olarak ilerleyen gebeliklerde bile ortaya çıkan fiziksel ve ruhsal değişikliklerin, gebe kadınları ciddi derecede etkileyebilmekteyken, gebeliğin riskli olmasının süreci daha da zorlu bir dönem haline getirmektedir. (Derya ve ark., 2018).

Riskli gebelikler ortak noktası olan sık hastane kontrolleri, bebeğin zarar görme intimali gibi nedenler annelerin gebeliğe uyumunu zorlaştırmak dışında ekstra zorlukları da beraberinde getiren yeni uyum süreci gerektirmekte ve gebelikte iyilik düzeyini olumsuz etkilemektedir (Aydemir \& Hazar, 2014). Gebelikte iyilik halinin etkilenmesiyle birlikte duygu ve düşünceler gebenin beden sağlığını sağlanmayı zorlaştırmakla kalmayıp, gebeliğin olumlu yönlerine odaklanma ve gebelik bakımının sağlanmasında yetersizliğe neden olabilmektedir (Dolatian, Mahmoodi, Dilgony, Shams \& Zaeri, 2017).

$\mathrm{Bu}$ bilgiler doğrultusunda fiziksel aktivite düzeyinin riskli gebeliğe sahip kişiler için önemini belirlemek, iyilik hallerine katkı sağlayıp gebelikteki pozitif iyilik hallerinin yanı sıra yaşam kalitelerini arttırmak daha büyük bir önem ve gereklilik ifade etmektedir. Literatür incelendiğinde ülkemizde riskli olan ve olmayan gebelerin fiziksel aktivitenin gebelik iyiliği, gebelik yakınmaları ve yaşam kalitesine etkisinin karşılaştırıldığı bir çalışmaya rastlanmamıştır. Bu gözlemden yola çıkarak araştırmada riskli olan ve olmayan gebelerin fiziksel aktivite düzeyleri, gebelikte iyilik ve gebelikteki yakınmaların yaşam kalitesine etkisini belirlemek planlanmıştır. Bu çalışmanın gebeleri takip eden sağlık çalışanlarına, gebelere sunacakları eğitim ve danışmanlık hizmetlerinin belirlenmesinde yol gösterici olacağı düşünülmekte ve literatüre katkı sağlaması beklenmektedir.

\section{Yöntem}

Araştırma kesitsel ve gruplar arası karşılaştırmalı nitelikte olarak yapıldı. Araştırma verileri Temmuz-Ağustos 2021 tarihleri arasında toplanmış olup, örneklemini bir kamu hastanesine doğum öncesi takipleri için başvuran gebeler oluşturmaktadır. T.C Sağlık Bakanlığı tarafından kullanılan 23 sorudan oluşan riskli gebe belirleme formu katılımcıların gebeliklerinin riskli olup olmadığını belirlemek için kullanıldı (TNSA 2018). Sağlıklı gebeler için; Sağlık Bakanlığı risk değerlendirme formunda yer almayan, iletişim sıkıntısı olmayan ve 20 hafta ve üzeri gebelik haftasına ulaşmış olan gebeler olarak belirlenmiştir.

Araştırmanın evreni Türkiye'nin doğusunda yer alan bir kamu hastanesine doğum öncesi takipleri için başvuran gebeler oluşturdu. Örneklem büyüklüğü power analizinde $\% 5$ yanılgı düzeyi çift yönlü önem düzeyinde \%95 güven aralığında, \%80 güçle 381 olarak hesaplandı. Araştırmada örneklem seçimine gidilmeden araştırmaya katılmaya gönüllü olan 155 riskli, 448 riskli olmayan toplam 603 gebe araştırma kapsamına alınmıştır.

\section{Veri toplama araçları}

Veriler araştırmacılar tarafından literatür taramasıyla oluşturulan Kişisel Bilgi Formu, Uluslararası Fiziksel Aktivite Anketi (UFAA), Gebelikte İyilik Ölçeği (GiÖ) ve Gebelikte Yakınmalar ve Yaşam Kalitesine Etkisi Ölçeği (GYYKÖ) ile toplandı.

\section{Kişisel Bilgi Formu}

Gebelerin bazı tanıtıcı özelliklerini belirlemek amacıyla araştırmacılar tarafından literatür taraması sonucu oluşturulmuş olan formda kadınların bazı sosyo-demografik (eğitim düzeyi, çalışma durumu vb.), obstetrik (ilk gebelik yaşı, gebeliğin planlı olma durumu vb.) özelliklerini belirleyen toplam 8 adet soru bulunmaktadır.

\section{Uluslararası Fiziksel Aktivite Anketi}

UFAA, Craig ve arkadaşları tarafından fiziksel aktivite düzeyini belirlemek amacıyla geliştirilmiş olup, son 1 haftada içindeki fiziksel aktivite düzeyini belirlemektedir. Form yedi sorudan oluşmakta olup, oturma, yürüme, orta düzeyde şiddetli aktiviteler ve şiddetli aktivitelerde harcanan zaman hakkında bilgi sağlamaktadır. Türkçe geçerlik ve güvenilirlik çalışması Öztürk tarafından yapılmıştır. Toplam skor elde edilen puana göre 3 aktivite seviyesinde (Düşük düzey= $<600$ MET$\mathrm{dk} / \mathrm{hafta}$, orta düzey $=600-3000 \mathrm{MET}-\mathrm{dk} / \mathrm{hafta}$, yüksek düzey $=>3000$ MET-dk/hafta) sınıflandırma yapılmaktadır (Öztürk, 2005).

\section{Gebelikte Iyilik Ölçeği}

Geçerlilik ve güvenilirliği Alderdice ve arkadaşları tarafından 2017 yılında geliştirilmiştir. Ölçek, gebelikte İyilik ölçümünün özelliklerini tanımlar ve genel iyilik önlemleriyle nasıl ilişkili olduğunu ölçer. Ölçekten alınan puan ortalaması arttıkça gebelikteki iyilik düzeyini de artmaktadır. Ölçeğin, Endişeler ile Pozitif Etki ve Memnuniyet olmak üzere iki alt boyutu yer almaktadır. Ölçeğin Cronbach's alfa değeri 0.73 olarak bulunmuştur. Ölçeğin Pozitif Etki ve Memnuniyet alt boyutu 0.71 , Endişeler alt boyutu ise 0.70 olarak bulunmuştur. (Alderdice 2017). Bu araştırmada, cronbach alfa güvenirlik ölçek toplam puanının 0.68, Pozitif Etki ve Memnuniyet alt boyutu puanının 0.71 ve Endişeler alt boyutu puanının 0.74 olduğu tespit edilmiştir.

\section{Gebelikte Yakınmalar ve Yaşam Kalitesine Etkisi Ölçeği}

Foxcroft ve arkadaşları tarafından gebelikte yaşanabilecek yakınmaların günlük yaşamı nasıl etkilediğini değerlendiren bir ölçektir. Ölçeğin geçerlik güvenirliği, 2016 yılında Özorhan tarafından yapılmıştır. Ölçekte, 42 madde bulunmakta ve iki bölümden oluşmaktadır. Birinci bölümde, gebelikte ortaya çıkan yakınmalardan son bir ay içerisinde ne kadar sıklıkla karşılaşıldığı değerlendirilmekte olup, birinci bölümden her bir yakınma için 1-3 arasında bir işaretleme yapılırsa, ölçeğin ikinci bölümüne geçilmektedir. İkinci bölüm de, yakınmaların günlük yaşam aktivitesini nasıl etkilediğini değerlendirilmektedir. Ölçeğin kesme noktası bulunmamak olup, toplam puan yükseldikçe, gebelik yakınmaları artmakta, yaşam kalitesi ise düşmektedir. Ölçeğin cronbach alfa güvenirlik katsayısı 0,91'dir (Özorhan 2016). Bu araştırmada, cronbach alfa güvenirlik katsayısının 0.92 olduğu tespit edilmiştir.

\section{İstatiksel Analiz}

Araştırma sonunda elde edilen veriler SPSS 25.0 for Windows yazılımı (SPSS, Chicago, II, USA) ile değerlendirildi. Sonuçları bildirirken, gebe kadınlar 2 gruba ayrıldı: (1) riskli 
gebeliğe sahip olanlar ve (2) riskli gebeliğe sahip olmayanlar. Tanımlayıcı istatistikler sayı, yüzde olarak verildi. Gruplar arasındaki farkın karşılaştırılmasında ki kare testi, parametrik test koşullarını sağlayan değişkenler için iki grup karşılaştırmalarında t-testi kullanıldı. Riskli olan ve olmayan gebelerin fiziksel aktivite, gebelik iyiliği ile gebelikte yakınmalar ve yaşam kalitesi üzerindeki etkisi lojistik regresyon analizi ile incelendi. İstatistiksel anlamlılık $p<0.05$ olarak belirlendi.

\section{Araştırmanın Etik Yönü}

Veriler toplanmadan önce Üniversite bünyesinde yer alan Sağıı Bilimleri Girişimsel Olmayan Klinik Araştırmalar ve Yayın Etik Kurulu'ndan etik onayı alındı (Karar No: 2021/2326, Tarih: 27.07.2021). Ayrıca anket formlarından önce araştırma ve veri toplama araçları hakkında bilgilendirilme yazısı oluşturularak katılımcıların onamları alındı. Çalışmaya katılım gönüllülük esasına göre gerçekleştirildi.

\section{Bulgular}

Katılımcıların sosyo-demografik ve obstetrik özelliklerinin riskli ve riskli olmayan gebeliğe sahip olma durumlarına göre karşılaştırılması Tablo 1'de sunulmuştur. Riskli gebeliğe sahip olan katılımcıların yaş ortalaması $30.81 \pm 5.27$, ilk gebelik yaş ortalamaları ise $23.72 \pm 4.23$ olarak belirlenirken, riskli olmayan gebeliğe sahip olanların yaş ortalaması $27.94 \pm 5.61$ ve ilk gebelik yaş ortalamalarının $22.97 \pm 3.49$ olduğu belirlendi. Riskli ve riskli olmayan gebeliğe sahip kadınların ilk gebelik yaşı ve gebeliğinin planlı olma durumu açısından gruplar arasında istatistiksel olarak önemli fark olduğu belirlendi $(p<0.05)$. Ancak eğitim seviyesi, çalışma durumu, sosyal güvence varlığı ve yaşadığı yer değişkenleri açısından gruplar arasında istatistiksel olarak önemli fark olmadığı belirlendi $(p>0.05)$ (Tablo 1).

Gebe kadınların UFAA, GiÖ ve GYYKEÖ ölçek ve alt boyutlarından elde edilen puan ortalamalarının riskli ve riskli olmayan gebeliğe sahip olma durumlarına göre karşılaştırılması Tablo 2'de sunulmuştur. Riskli ve riskli olmayan gebeliğe sahip gruplar arasında UFAA toplam ile şiddetli ve orta fiziksel aktivite alt boyutları, GiÖ toplam ve tüm alt boyutları (Pozitif etki ve Memnuniyet, Endişeler) ile
GYYKEÖ açısından fark istatistiksel olarak anlamlı bulundu $(p<0.05)$. Riskli gebeliğe sahip olan gebelerin toplam, şiddetli ve orta düzeyde fiziksel aktivite düzeylerinin riskli olmayan gebelere göre daha düşük olduğu belirlendi. Aynı zamanda riskli gebeliğe sahip katılımcıların gebelik pozitif etki ve memnuniyet düzeyleri daha düşük bulurken, endişe düzeylerinin daha yüksek olduğu belirlendi. Riskli gebeliğe sahip olan katılımcıların daha yüksek düzeyde gebelik yakınmaları yaşadıkları ve yaşam kalitelerinin de daha düşük düzeyde olduğu belirlendi. Ancak UFAA'nın yürüme fiziksel aktivitesi alt boyutu açısından gruplar arasında istatistiksel olarak anlamlı bir fark olmadığı belirlendi $(p>0.05)$ (Tablo 2). Lojistik regresyon analizi, şiddetli fiziksel aktivite $(\mathrm{OR}=1.001)$ ile orta düzeyde fiziksel aktivite $(O R=1.001)$ ve gebelikte pozitif etki ve memnuniyet $(\mathrm{OR}=1.030)$ riskli olmayan gebelerde artmış olduğunu gösterdi (Tablo 3). Ayrıca gebelikte endişeler $(\mathrm{OR}=0.900)$ ile gebelikte yakınmaları artarken, yaşam kalitesinin $(\mathrm{OR}=0.986)$ riskli olan gebelerde düşmüş olduğunu gösterdi (Tablo 3).

\section{Tartışma}

Riskli gebeliğe sahip kadınlar fiziksel ve duygusal olarak gebelikleri süresince riskli olmayan gebelere göre daha fazla etkilenmektedirler. Özellikle sık sağlık kontrolleri duygu ve düşünceleri olumsuz etkilemekle kalmayıp gebe kadınların kendine olan güveni ve enerjisini azaltmaktadır. Çalışmamızda, riskli olan ve olmayan gebelerin fiziksel aktivite düzeyleri, gebelikte iyilik ve gebelikteki yakınmaların yaşam kalitesine etkisini belirlemek amaçlanmıştır.

Fiziksel egzersizin maternal faydaları ve koruyuculuğu egzersizin tipine ve yöntemine bağlı olarak değişiklik göstermektedir. Literatürde yer alan çalışmalar bisiklet sürme, basketbol oynamak gibi şiddetli egzersizler arasında yer alan egzersizlerin kilo kontrolünü sağlama, fiziksel kondisyonu koruma ve desteklemenin yanı sıra hipertansif hastalıklar, preeklemsi, diyabet gibi sistemik hastalık riskini azaltmada klinik etkinlik gösterdiğini belirtmektedir(Lamina \& Agbanusi, 2013; Goker, Yanikkerem \& Topsakal 2021, Davoud \& Abazari, 2020).

Tablo 1. Katılımcıların sosyodemografik ve obstetrik özelliklerinin gebelik durumlarına göre karşılaştırılması $(n=603)$

\begin{tabular}{|c|c|c|c|c|c|c|c|}
\hline \multirow[t]{2}{*}{ Özellikler } & \multicolumn{2}{|c|}{$\begin{array}{l}\text { Riskli Olan } \\
(n=155)\end{array}$} & \multicolumn{2}{|c|}{$\begin{array}{c}\text { Riskli Olmayan } \\
(n=448)\end{array}$} & \multicolumn{2}{|c|}{$\begin{array}{l}\text { Toplam } \\
(n=603)\end{array}$} & \multirow[t]{2}{*}{$\begin{array}{l}\text { Test ve } p \\
\text { değeri }\end{array}$} \\
\hline & $\mathbf{n}$ & $\%$ & $\mathbf{n}$ & $\%$ & $\mathbf{n}$ & $\%$ & \\
\hline Yaş, y (Ort土SS) & \multicolumn{2}{|c|}{$30.81 \pm 5.27$} & \multicolumn{2}{|c|}{$27.94 \pm 5.61$} & \multicolumn{2}{|c|}{$28.68 \pm 5.72$} & $\begin{array}{l}t=0.901 \\
p=0.368\end{array}$ \\
\hline İlk gebelik yaş, y (OrtıSS) & \multicolumn{2}{|c|}{$23.72 \pm 4.23$} & \multicolumn{2}{|c|}{$22.97 \pm 3.49$} & \multicolumn{2}{|c|}{$23.17 \pm 3.70$} & $\begin{array}{l}t=1.435 \\
p=0.152\end{array}$ \\
\hline \multicolumn{8}{|l|}{ İlk gebelik yaşı } \\
\hline$\leq 25$ & 95 & 61.3 & 341 & 76.1 & 436 & 72.3 & $x^{2}=9.868$ \\
\hline$\geq 26$ & 60 & 38.7 & 107 & 23.9 & 167 & 27.7 & $p<0.002$ \\
\hline \multicolumn{8}{|l|}{ Eğitim seviyesi } \\
\hline$\leq$ Lise ve altı & 114 & 73.5 & 343 & 76.6 & 457 & 75.8 & $x^{2}=0.570$ \\
\hline $\begin{array}{l}\geq \text { Üniversite ve üzeri } \\
\text { Çalışma durumu }\end{array}$ & 41 & 26.5 & 105 & 23.4 & 146 & 24.2 & $p=0.450$ \\
\hline Çalışıyor & 24 & 15.5 & 54 & 12.1 & 78 & 12.9 & $x^{2}=1.203$ \\
\hline \multicolumn{8}{|l|}{ Sosyal güvence } \\
\hline Var & 125 & 80.6 & 363 & 81.0 & 488 & 80.9 & $x^{2}=0.011$ \\
\hline \multicolumn{7}{|l|}{ Yaşadığı yer } & $p=0.917$ \\
\hline İ & 109 & 70.3 & 305 & 68.1 & 414 & 68.7 & $x^{2}=0.615$ \\
\hline İlçe & 29 & 18.7 & 97 & 21.7 & 126 & 20.9 & $p=0.735$ \\
\hline Köy & 17 & 11.0 & 46 & 10.3 & 63 & 10.4 & \\
\hline \multicolumn{8}{|l|}{ Gebeliğin planlı olması } \\
\hline Evet & 123 & 79.4 & 412 & 92.0 & 535 & 88.7 & $x^{2}=18.300$ \\
\hline Hayır & 32 & 20.6 & 36 & 8.0 & 68 & 11.3 & $p<0.001$ \\
\hline
\end{tabular}


Tablo 2. Riskli ve riskli olmayan gebeliğe sahip olma durumuna göre UFAA, GïÖ ve GYYKEÖ ölçeklerinden alınan puan ortalamalarının karşılaştırııması $(n=603)$

\begin{tabular}{|c|c|c|c|c|}
\hline \multirow[t]{2}{*}{ Değişkenler } & $\begin{array}{c}\text { Riskli Olan } \\
(n=155)\end{array}$ & $\begin{array}{c}\text { Riskli Olmayan } \\
(n=448)\end{array}$ & \multirow[t]{2}{*}{ Test $^{\star}$} & \multirow[t]{2}{*}{$p$ değeri } \\
\hline & Ort $\pm S S$ & 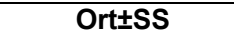 & & \\
\hline UFAA Toplam & $999.93 \pm 1977.99$ & $1853.57 \pm 2420.03$ & -4.361 & $p<0.001$ \\
\hline Şiddetli fiziksel aktivite & $116.69 \pm 456.57$ & $565.71 \pm 1376.91$ & -6.013 & $p<0.001$ \\
\hline Orta fiziksel aktivite & $94.96 \pm 334.46$ & $403.75 \pm 856.07$ & -6.359 & $p<0.001$ \\
\hline Yürüme fiziksel aktivite & $788.27 \pm 1796.25$ & $884.11 \pm 1361.49$ & -0.693 & $\mathrm{p}=0.489$ \\
\hline Giö Toplam & $31.47 \pm 8.34$ & $29.87 \pm 7.73$ & 2.170 & $p=0.030$ \\
\hline Giö- Pozitif Etki ve Memnuniyet & $14.99 \pm 5.89$ & $16.26 \pm 5.67$ & -2.331 & $p=0.021$ \\
\hline Gïö- Endişeler & $16.48 \pm 6.28$ & $13.61 \pm 4.63$ & 5.208 & $p<0.001$ \\
\hline GYYKEÖ & $74.55 \pm 21.82$ & $67.37 \pm 27.38$ & 3.295 & $p=0.001$ \\
\hline
\end{tabular}

* Bağımsız gruplarda t-testi, UFAA: Uluslararası Fiziksel Aktivite Anketi, GiÖ: Gebelikte İyilik Ölçeği, GYYKEÖ: Gebelikte Yakınmalar ve Yaşam Kalitesine Etkisi Ölçeği

Tablo 3. Lojistik regresyon analizi sonuçları

\begin{tabular}{|c|c|c|c|c|c|c|c|}
\hline & \multirow[b]{2}{*}{ B } & \multirow[b]{2}{*}{ S.E. } & \multirow[b]{2}{*}{ df } & \multirow[b]{2}{*}{$\mathbf{P}$} & \multirow[b]{2}{*}{ OR } & \multicolumn{2}{|c|}{$95 \% \mathrm{Cl}$} \\
\hline & & & & & & Lower & Upper \\
\hline UFAA- Şiddetli fiziksel aktivite & 0.001 & 0.000 & 1 & 0.000 & 1.001 & 1.000 & 1.001 \\
\hline UFAA- Orta fiziksel aktivite & 0.001 & 0.000 & 1 & 0.002 & 1.001 & 1.000 & 1.002 \\
\hline UFAA-Yürüme fiziksel aktivite & 0.000 & 0.000 & 1 & 0.674 & 1.000 & 1.000 & 1.000 \\
\hline GïÖ- Pozitif Etki ve Memnuniyet & 0.039 & 0.019 & 1 & 0.046 & 1.030 & 0.993 & 1.068 \\
\hline GiÖ- Endişeler & -0.092 & 0.021 & 1 & 0.000 & 0.900 & 0.864 & 0.937 \\
\hline GYYKEÖ & 0.014 & 0.004 & 1 & 0.000 & 0.986 & 0.978 & 0.994 \\
\hline
\end{tabular}

UFAA: Uluslararası Fiziksel Aktivite Anketi, GiÖ: Gebelikte İyilik Ölçeği, GYYKEÖ: Gebelikte Yakınmalar ve Yaşam Kalitesine Etkisi Ölçeği

Düşük tempolu yürüyüşler gibi hafif ila orta şiddette yapılan egzersizlerin ise, gebelikte herhangi bir komplikasyon olmaksızın kas direncini ve esnekliğini geliştirmede, sırt ağrısı, ödem gibi gebelik semptomlarını azaltmada, ruh sağlığını iyileştirme ve yaşam kalitesini artırmada önemli rol oynadığı çalışmalar tarafından ifade edilmektedir (Pennick \& Liddle, 2013; Leite ve ark., 2017; Oostdam, van Poppel, Eekhoff, Wouters \& van Mechelen, 2009; Deierlein, Siega-Riz \& Evenson, 2012; Chasan-Taber ve ark., 2014). Amerikan Kadın Hastalıkları Ve Doğum Uzmanları Koleji (ACOG 2002), tıbbi veya obstetrik komplikasyonları olmayan gebe kadınlar için, haftanın tamamında olmasa da en az 3 gününde en az 30 dakika hafif tempolu yürüyüş gibi orta şiddette egzersizler yapılmasını önermektedir (ACOG, 2002). Kraliyet Kadın Hastalıkları ve Doğum Uzmanları Koleji (RCOG), tüm hamile kadınların sağlıklı yaşam tarzının bir parçası olarak hafif ve orta şiddetli olan egzersizlere katılmaları ve devamlıığını sağlamaları için teşvik edilmesi gerektiğinin altını çizerek konuya dikkat çekmektedir (RCOG, 2015). Çalışmamızda riskli gebeliğe sahip kadınların, riskli gebeliğe sahip olmayan kadınlara göre istatiksel olarak da anlamlılık gösterecek şekilde daha düşük düzeyde fiziksel aktivite yaptıkları belirlendi. Aynı zamanda aktivite çeşitlerine bakıldığında da aerobik, bisiklet sürme gibi egzersizleri içeren şiddetli fiziksel aktivite düzeyleri ile dans etme, hafif yük taşıma egzersizlerini içeren orta düzeyde fiziksel aktivite düzeylerinde de daha düşük olduğu bulundu $(p<0.05)$. Yürüme fiziksel egzersizinin riskli gebelerde daha düşük düzeyde olduğu ancak gruplar arasındaki farkın istatistiksel olarak anlamlı olmadığı belirlendi ( $p>0.05)$. Ayrıca çalışmamızda logistik regresyon bulgusu olarak şiddetli (OR: 1.001) ve orta düzeyde (OR: 1.001) yapılan fiziksel aktivenin riskli gebeliğe karşı koruyucu rol oynadığı belirlenmiştir. Bu bulgular ACOG ve RCOG'un riskli olan ve olmayan tüm gebeler için yaptığı önerileriyle paralellik göstermektedir.

Bu çalışmada GiÖ toplam ve alt boyutları puan ortalamaları gruplar arasında karşılaştırıldığında riskli gebeliğe sahip olanların iyilik halleri ile pozitif etki ve memnuniyet düzeylerinin anlamlı düzeyde daha düşük olduğu belirlendi. Aynı zamanda riskli gebeliğe sahip olan gebe kadınların Gï̈ endişe alt boyutundan aldıkları puan ortalamalarının da anlamlı düzeyde daha yüksek olduğu belirlendi. Literatürde yer alan çalışmalar bulgularımızla benzer şekilde, gebelikte ortaya çıkan gebelik semptomları ile sistematik ve psikolojik bozukluk riski arasında pozitif yönde ilişki olduğunu göstermektedir (Dorheim, Bjorvatn \& Eberhard-Gran, 2012; Osnes, Roaldset, Follestad \& Eberhard-Gran, 2019). Normal gebeliklere kıyasla, riskli gebeliklerde yaşanan stres, travma ve endişe maternal- fetal sağlık sorunların olması nedeniyle daha yüksek düzeydedir (Karabulutlu \& Yavuz, 2021). Riskli olan ve olmayan gebelerin psiko-sosyal sağlıklarının karşılaştırıması amacıyla 108'i riskli olan 232 gebeyle yapılan çalışmada riskli olan gebelerin stres, kaygı ve bunlara bağlı endişe yaşama durumunun riskli olmayan gebelere oranla daha yüksek düzeyde olduğu bildirilmiştir (Gümüşdaş, Apay, \& Özorhan, 2014). Progresif kas gevşeme egzersizlerinin gebelerin yaşadıkları distres düzeyi, gebelikte annelik ve beden algısı üzerine etkisinin değerlendirilmek amacıyla dört hafta boyunca progresif kas gevşeme egzersizleri yaptırılan seksen üç gebenin dâhil edildiği deneysel bir çalışmada fiziksel aktivitenin gebelik algısı ve memnuniyetini olumlu yönde arttırdığı belirtilmiştir (Dikmen \& Şanlı, 2019). Seksen üç gebe ile yapılan bu çalışma sonucuyla benzer olarak çalışmamızda özellikle sağlıklı gebeliğe sahip olan kadınların fiziksel aktivite düzeylerinin yüksek olması aynı zamanda gebelikte iyilik düzeylerine de pozitif etki ettiği ve memnuniyetlerinin de daha yüksek olmasına katkı sağladığı düşünülmektedir. Bu bulgu ayrıca lojistik regresyon analiziyle de desteklenmektedir. Gebelikte endişelerin $(\mathrm{OR}=0.900)$ varlığı ve düzeyleri üzerinde riskli gebelikler ön görücü rol oynarken, gebelikte pozitif etki ve memnuniyet $(\mathrm{OR}=1.030)$ varlığı ve düzeyleri üzerinde riskli olmayan gebeliğe sahip olmanın ön görücü rol oynadığı çalışmamızda belirlenmiştir.

Gebelik süresince farklılık gösteren hormonal ve fiziksel değişiklikler, gebe kadının hem fiziksel hem ruhsal durumunu 
etkilemekle kalmayıp yaşam kalitesinde de değişikliğe neden olmaktadır. Literatür taramasında riskli olan ve olmayan gebelerin yakınmaları ve yaşam kalitelerinin karşılaştırıldığı bir çalışmaya rastlanmamış olsa da, riskli gebelerin yaşadığı fiziksel semptomların olumsuz duygu ve endişelerle birlikte gebelik yakınmalarını da arttırıp yaşam kaliteleri olumsuz etkilediği belirtilmiştir (Kıratlı \& Yavan, 2021). Can ve arkadaşları tarafından gebelerin son trimesterde yaşam kalitesini değerlendirmek ve gebelikte yaşadığı sorunları belirlemek amacıyla yapılan çalışmada hiperemezis, konstipasyon, mide problemi gibi gebelik semptomları yaşayan gebelerin yaşam kalitelerinin daha düşük düzeyde olduğu belirlenmiştir (Can, Yılmaz, Çankaya \& Kodaz, 2019). İki yüz kırk bir gebe ile yapılan başka bir çalışmada da gebelik semptomlarının yaşam kalitesini olumsuz yönde etkilediği vurgulanmıştır (Şahan 2020). Riskli gebelikler; hiperemezis gravidarum, preeklemsi, anemi gibi sistemik hastalıklarında yer aldığı ve gebenin yaşam kalitesini doğrudan olumsuz etkileyen bir süreçtir (Şahan \& Ege, 2020). Riskli gebelikler; hiperemezis gravidarum, preeklemsi, anemi gibi sistemik hastalıklarında yer aldığı ve gebenin yaşam kalitesini doğrudan olumsuz etkileyen bir süreçtir (Karabulutlu \& Yavuz, 2021). Bu çalışmada riskli gebelerin GYYKEÖ puan ortalamalarının riskli olmayan gebelere göre anlamlı derecede yüksek olduğu belirlendi. Literatürde yer alan çalışmalarla paralel şekilde çalışmamızda lojistik regresyon sonucuyla riskli gebeliğin artmış gebelik yakınmaları ile birlikte düşük yaşam kalitesinin ön görücüsü olduğu belirlendi (OR=0.986).

\section{Araştırmanın Sınırlılıkları}

Bu çalışmanın çalışmanın kesitsel tipte karşılaştırmalı olarak yapılmış olması, sonucun nedensellik yönünden değerlendirilmesini engellemekte olup, bu çalışmanın sınırlıı̆ını oluşturmaktadır. Çalışmanın bir diğer sınırlılığı ise, tek merkezli olarak yapılmış olmasıdır. Bu nedenle araştırma sonuçları genellenemez. İleride yapılacak çalışmaların daha büyük bir örneklem grubuyla yapılması önerilebilir.

\section{Sonuç ve Öneriler}

Çalışmamızda, riskli gebeliğe sahip olmanın fiziksel aktivite düzeyi, gebelikteki iyilik düzeyleri ile gebelik yakınmaları ve yaşam kalitesini etkilediği belirlendi. İlk gebelik yaşı ve gebeliğin planlı olması gibi obstetrik değişkenlerin riskli gebeliğe sahip olmada belirleyici rol oynayan değişkenlerden olduğu belirlendi. Ayrıca fiziksel aktivite düzeyinin gebelikte iyilik hali düzeyi ve gebelik yakınmaları ile ilişkili olduğu belirlendi. Gebelikte yapılan orta ve şiddetli düzeyde fiziksel aktivitenin, gebelikte yüksek pozitif etki ve memnuniyete sahip olma ile düşük düzeyde gebelik yakınmalarına sahip olmanın riskli gebelik yaşama riskini arttırdığı belirlenmiştir. Buna karşın, yürüme düzeyinde yapılan fiziksel aktivite düzeyinin riskli gebeliğe sahip olma riski üzerine anlamlı etkiye sahip olmadığı belirlendi.

Sağlık çalışanları; fiziksel aktivite düzeyi düşük olan ve yüksek gebelik endişesine sahip olan gebelerin riskli gebelik ve yüksek düzeyde gebelik yakınmaları yaşama olasılığını azaltmak için özellikle bilgilendirici olmalı. Ebeler ve sağlık çalışanları kadınların gebelik durumlarının yanı sıra fiziksel ve duygusal özelliklerinin nasıl ve ne şekilde etkileri olabileceğini bilmeli ve gerekli eğitimler sağlanmalıdır.

\section{Çıkar Çatışması}

Çıkar çatışması bulunmamaktadır.

\section{Teşekkür} ederiz.

Bu çalışmaya gönüllü olarak katılan katılımcılara teşekkür

\section{Finansal Destek}

Bu çalışmada finansal destek alınmamıştır

\section{Etik Komite Onayı}

Araştırma için Sağlık Bilimleri Girişimsel Olmayan Klinik Araştırmalar ve Yayın Etik Kurulu'ndan etik onayı alındı (Karar No: 2021/2326, Tarih: 27.07.2021).

\section{Bilgilendirilmiş Onam}

Çalışmaya katılanlardan onam alınmıştır.

\section{Hakem Değerlendirmesi}

Dış bağımsız.

\section{Yazar Katkıları}

E.S.B.: Tasarım, Metodoloji, Veri Toplanması, Veri analizi, Eleştirel İnceleme, Makale yazımı

T.U.: Metodoloji, Eleştirel İnceleme, Makale Yazımı

\section{Kaynaklar}

American College of Obstetricians and Gynecologists (ACOG) committee opinion (2002). Exercise during pregnancy and the postpartum period. Number 267, January 2002. International Journal of Gynecology \& Obstetrics, 77, 79-81.

Alderdice, F., McNeill, J., Gargan, P., \& Perra, O. (2017). Preliminary evaluation of the Well-being in Pregnancy (WiP) questionnaire. Journal of Psychosomatic Obstetrics \& Gynecology, 38(2), 133142.

Aydemir, H., \& Hazar, U. (2014). Düşük riskli, riskli, yüksek riskli gebelik ve ebenin rolü. Gümüşhane Üniversitesi Sağlık Bilimleri Dergisi, 3(2), 815-833

Can, R., Yılmaz, S. D., Çankaya, S., \& Kodaz, N. (2019). Gebelikte yaşanan sorunlar ve yaşam kalitesi ile ilişkisi. Sağlık ve Toplum, 29(2), 58-64.

Chasan-Taber, L., Silveira, M., Lynch, K.E., Pekow, P., Braun, B., Manson, J. E., Solomon, C. G., \& Markenson, G. (2014). Physical activity before and during pregnancy and risk of abnormal glucose tolerance among Hispanic women. Diabetes \& Metabolism, 40(1), 67-75.

Cioffi, J., Schmied, V., Dahlen, H., Mills, A., Thornton, C., Duff, M., ... \& Kolt, G. S. (2010). Physical activity in pregnancy: women's perceptions, practices, and influencing factors. Journal of Midwifery \& Women's Health, 55(5), 455-461.

Cramp, A. G., \& Bray, S. R. A. (2009). Prospective examination of exercise and barrier self-efficacy to engage in leisure time physical activity during pregnancy. Annals of Behavioral Medicine, 37(3), 325-334.

Daşıkan, Z., Güner, Ö., \& Bozkurt, T. (2019). İkinci ve üçüncü trimester gebelerin fiziksel aktivite düzeyi ve fiziksel aktivite engelleri. Adıyaman Üniversitesi Sağlık Bilimleri Dergisi, 5(3), 1731-1745.

Davoud, A., \& Abazari, M. (2020). The relationship between quality of life and physical activity, worry, depression, and insomnia in pregnant women. Iranian Journal of Psychiatry, 15(2), 159.

Deierlein, A. L., Siega-Riz, A. M., \& Evenson, K. R. (2012). Physical activity during pregnancy and the risk of hyperglycemia. Journal of Women's Health, 21, 769-775.

Derya, Y. A., Özşahin, Z., Uçar, T., Erdemoğlu, Ç., \& Ünver, H. (2018) Gebelikteki yakınmaların yaşam kalitesine etkisi ile psikososyal sağlık düzeyi arasındaki ilişkinin incelenmesi. Turkish Journal of Family Medicine and Primary Care, 12(3), 171-177.

Dikmen, H. A., \& Şanlı, Y. (2019). Progresif kas gevşeme egzersizlerinin gebelerin distres düzeyi ve gebelik algısına etkisi. Dokuz Eylül Üniversitesi Hemşirelik Fakültesi Elektronik Dergisi, 12(3), 186-198. 
Dolatian, M., Mahmoodi, Z., Dilgony, T., Shams, J., \& Zaeri, F. (2017). The structural model of spirituality and psychological well-being for pregnancy-specific stress. Journal of Religion and Health, 56(6), 2267-2275.

Dorheim, S. K., Bjorvatn, B., \& Eberhard-Gran, M. (2012). Insomnia and depressive symptoms in late pregnancy: a population-based study. Behavioral Sleep Medicine, 10(3),152-166.

Downs, D. S., Chasan-Taber, L., Evenson, K. R., Leiferman, J., \& Yeo, S. (2012). Physical activity and pregnancy: past and present evidence and future recommendations. Research Quarterly for Exercise and Sport, 83(4), 485-502.

Evenson, K. R., Barakat, R., Brown, W. J., Dargent-Molina, P., Haruna, M., Mikkelsen, E. M., ... \& Yeo, S. (2014). Guidelines for physical activity during pregnancy: comparisons from around the world. American Journal of Lifestyle Medicine, 8(2), 102-121.

Evenson, K. R., Moos, M. K., Carrier, K., \& Siega-Riz, A. M. (2009). Perceived barriers to physical activity among pregnant women. Maternal and Child Health Journal, 13(3), 364.

Goker, A. G., Yanikkerem, E., \& Topsakal, Ö. (2021). Gebelerin fiziksel aktivite düzeyleri ve yaşam kalitelerinin incelenmesi. Celal Bayar Üniversitesi Sağlık Bilimleri Enstitüsü Dergisi, 8(2), 315-322.

Gümüşdaş, M., Apay, S. E., \& Özorhan, E. Y. (2014). Riskli olan ve olmayan gebelerin psiko-sosyal sağlıklarının karşılaştıııması. Sağlık Bilimleri ve Meslekleri Dergisi, 1(2), 32-42.

Hacettepe Üniversitesi Nüfus Etütleri Enstitüsü. 2018 Türkiye Nüfus ve Sağlık Araştırması, Ankara, T.C. Sağlık Bakanlığı ve TÜBiTAK, 2014.

http://www.hips.hacettepe.edu.tr/tnsa2013/rapor/TNSA_2018_ana_ rapor.pdf. pdf adresinden erişildi. Erişim tarihi: 30 Haziran 2021

Hui, A., Back, L., Ludwig, S., Gardiner, P., Sevenhuysen, G., Dean, H., ... \& Shen, G. X. (2012). Lifestyle intervention on diet and exercise reduced excessive gestational weight gain in pregnant women under a randomised controlled trial. BJOG: An International Journal of Obstetrics \& Gynaecology, 119(1), 70-77.

Karabulutlu, Ö., \& Yavuz, C. (2021). Yüksek riskli gebeliklerde depresyon ve anksiyete düzeylerinin sıklığının değerlendirilmesi. Caucasian Journal of Science, 8(1), 51-69.

Kıratı, D., \& Yavan, T. (2021). Gebelikte bulantı kusma yaşama durumu, etkileyen faktörler ve baş etme yöntemlerinin belirlenmesi. İzmir Katip Çelebi Üniversitesi Sağlık Bilimleri Fakültesi Dergisi, 6(2), 21-29.
Lamina, S., \& Agbanusi, E. (2013). Effect of aerobic exercise training on maternal weight gain in pregnancy: a meta-analysis of randomized controlled trials. Ethiopian Journal of Health Sciences, 23, 59-64.

Leite, C. F., do Nascimento, S. L., Helmo, F. R., dos Reis Monteiro, M. L. G., Dos Reis, M. A., \& Corrêa, R. R. M. (2017). An overview of maternal and fetal short and long-term impact of physical activity during pregnancy. Archives of Gynecology and Obstetrics, 295(2), 273-283.

Nascimento, S. L., Surita, F. G., Godoy, A. C., Kasawara, K. T., \& Morais, S. S. (2015). Physical activity patterns and factors related to exercise during pregnancy: a cross sectional study. PloS One, 10(6), e0128953.

,Oostdam, N., van Poppel, M. N., Eekhoff, E. M., Wouters, M. G., \& van Mechelen, W. (2009). Design of FitFor 2 study: the effects of an exercise program on insulin sensitivity and plasma glucose levels in pregnant women at high risk for gestational diabetes. BMC Pregnancy Childbirth, 9(1), 1-9.

Osnes, R. S., Roaldset, J. O., Follestad, T., \& Eberhard-Gran, M. (2019). Insomnia late in pregnancy is associated with perinatal anxiety: A longitudinal cohort study. Journal of Affective Disorder, 248,155-165.

Özorhan, E. Y. (2016). Gebelikteki yakınmalar ve yaşam kalitesine etkisi ölçeğinin Türkçe geçerlilik ve güvenilirlik çalışması (Doktora Tezi). Atatürk Üniversitesi, Erzurum.

Öztürk, M. (2005). Validity and reliability of the International Physical Activity Questionnaire and determination of physical activity levels of students studying at the university (Master's thesis). University of Hacettepe, Ankara.

Pennick, V., \& Liddle, S. D. (2013). Interventions for preventing and treating pelvic and back pain in pregnancy. Cochrane database Syst Rev 8:CD001139.

Royal College of Obstetricians and Gynaecologists (RCOG) (2015). Exercise in pregnancy. https://www.rcog.org.uk/en/guidelinesresearch-services/guidelines/exercise-in-pregnancy-statementno.4/. pdf adresinden erişildi. Erişim tarihi: 30 Haziran 2021

Şahan, Ö., \& Ege, E. (2020). Erken gebelik döneminde yaşanan bulantı kusmanın sıkığı ve yaşam kalitesine etkisi. Hemşirelik Bilimi Dergisi, 3(1), 7-11. 